\title{
The Limits of HCD
}

\author{
Reimagining the Anthropocentricity of ISO 9241-210
}

\author{
Vanessa Thomas \\ HighWire Centre for Doctoral \\ Training \\ Lancaster University \\ Lancaster, UK \\ v.thomas1@lancaster.ac.uk
}

\author{
Christian Remy \\ Department of Informatics \\ University of Zurich \\ Zurich, Switzerland \\ remy@ifi.uzh.ch
}

\author{
Oliver Bates \\ School of Computing and \\ Communications \\ Lancaster University \\ Lancaster, UK \\ o.bates@lancaster.ac.uk
}

\begin{abstract}
Human-centred design (HCD) is just that: human-centred. As we approach the limits of Earth's biophysical systems, it no longer feels appropriate to place humans at the centre of design decisions. Yet HCD and its ISO-ISO-9241-210:2010-continue to be powerful and popular tools within many computing and design departments, as well as in their affiliated industries. These design approaches are perpetuating the trend of incremental improvements to the living standards of the already privileged and digitally connected whilst ignoring the broader environmental and socio-political effects of digital technologies. In this paper, we attempt to reimagine HCD and its ISO by drawing on fields and concepts such as sustainable interaction design (SID), animal-computer interaction (ACI), and object oriented ontology (OOO). Through this, we contribute a preliminary set of proposals about what needs to change with HCD and its ISO. We close by discussing the ISO development process and suggesting routes for environmentally concerned researchers to influence the evolution of HCD's ISO.
\end{abstract}

\section{CCS CONCEPTS}

-General and $\rightarrow$ Computing standards, RFCs and guidelines; -Human-centered computing $\rightarrow \mathrm{HCI}$ design and evaluation methods; HCI theory, concepts and models; User centered design; •Social and professional topics $\rightarrow$ Governmental regulations;

\section{KEYWORDS}

Human-centred design; standards; ISO; sustainable interaction design; animal-computer interaction; object oriented ontology.

ACM Reference format:

Vanessa Thomas, Christian Remy, and Oliver Bates. 2017. The Limits of HCD. In Proceedings of LIMITS'17, fune 22-24, 2017, Santa Barbara, CA, USA, , 8 pages.

DOI: http://dx.doi.org/10.1145/3080556.3080561

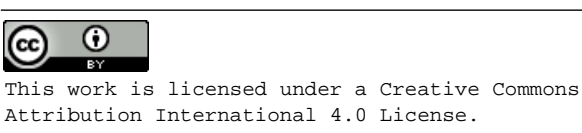

LIMITS'17, June 22-24, 2017, Santa Barbara, CA, USA (C) 2017 Copyright held by the owner/author(s). ACM ISBN 978-1-4503-4950-5/17/06 DOI: http://dx.doi.org/10.1145/3080556.3080561

\section{INTRODUCTION}

It is March 2017 and alarming environmental news appears to have become the norm: over $90 \%$ of the world's population breathes unhealthy air [25], significant Antarctic glacier melt continues unabated [45], and high levels of industrial toxins have infected deep sea marine life [17]. We are pushing the limits of Earth's biophysical systems, at least in terms of maintaining current living standards [41], and we need to drastically rethink many of our industries if we wish to alter course. This includes drastically rethinking the digital technology industry. Despite efforts from many tech companies, governmental bodies, and research communities, the environmental footprint of computing continues to grow [1, 11, 31, 35]. As members of the LIMITS community have argued and demonstrated, our conceptualisations and implementations of many facets of the digital technology industry need to change [5, 29, 30, 39].

In this paper, we examine and discuss human-centred design (HCD): "an approach to interactive systems development that aims to make systems usable and useful by focusing on the users, their needs and requirements, and by applying human factors/ergonomics, and usability knowledge and techniques" [16]. Given the aforementioned limits of earth's biophysical systems, we believe that placing human "needs and requirements" at the centre of design decisions no longer feels sufficient or appropriate. We use this paper to question that centring of human "needs and requirements", which we refer to using the term anthropocentricity. We focus specifically on HCD and its ISO for three reasons: 1) HCD is an incredibly popular and powerful approach in academia, industry, and governmental organisations, within digital design communities and beyond [40]; 2) the clear anthropocentricity of HCD-baked into its name and ethos-suggests that it needs to be reconsidered in the face of growing environmental and socio-political challenges, and; 3) HCD's ISO is a globally influential instrument of $\mathrm{HCD}-$ one that we have an opportunity to influence through the international standards development process.

By questioning the anthropocentricity of HCD and its ISO, we are not (yet) intentionally calling for their complete disbanding or abandonment; such an aggressive stance might isolate the broader research communities, governemntal bodies, and industries that rely on $\mathrm{HCD}$, which could be counterproductive to addressing our underlying concerns about HCD. Moreover, taking such an aggressive stance would require a different scale and depth of analysis than we are currently capable of conducting. Rather, we use this paper to build upon a discussion started by Schweikardt in 2009 [38] and offer a preliminary reimagining of the scope, principles, and activities related to HCD's ISO. We highlight opportunities to build on 
the existing, if narrowly focused, strengths of HCD and its ISO by drawing on sustainable interaction design (SID), animal-computer interaction (ACI), and object oriented ontology (OOO). We chose those fields and concepts partially due to our familiarity with and interest in them. We also believe they offer unique and alternative perspectives about the "needs and requirements" of ecosystems, animals, and our existing objects. Other theories and concepts-such as sustainable engineering, environmental determinism, political ecology, and materiality-might offer different and complementary perspectives, and we encourage other researchers to contribute those perspectives to our discussion.

Our discussion paper is structured as follows: we begin by introducing HCD and its ISO. We then describe some of the existing critiques of $\mathrm{HCD}$, noting how they fall short of fully addressing our concerns related to environmental ecosystems, animals, and existing objects. Following this, we briefly introduce Sustainable Interaction Design (SID), Object Oriented Ontology (OOO), animalcomputer interaction (ACI), and earth systems science, and what we believe they will offer to HCD and its ISO. We then highlight specific changes that could be made to section 4 of the HCD ISO, which covers the principles of HCD; these adjustments would build upon the existing strengths of HCD while integrating the environmental, animal, and object-oriented perspectives of SID, ACI, and OOO. Through this, we contribute a preliminary set of ideas about what should change with HCD and its ISO. We close by calling for researchers to engage with the future development of HCD's ISO.

\section{HCD AND ISO 9241-210:2010}

Human-centred design is an established approach for bringing people, their needs, social contexts, and requirements into design processes $[8,9,40]$. HCD emerged as an alternative to the narrow "user-centred" approaches that previously dominated ergonomics, computer science, and artificial intelligence projects $[8,9]$. These user-centred projects often involved designers who were interested in "optimizing the characteristics of [a] product, system or service based on a set of fixed preconceived cognitive plans and schema" [9]. This approach was critiqued for the ineffective and unsuccessful products it generated [8]. Human-centred design offered an appealing alternative to these ineffective products because it had no fixed, preconceived cognitive plans or schema; rather it provided techniques and activities that could draw insights and directions from the people who might use a product, system, or service $[9,40]$.

$\mathrm{HCD}$ is now at the core of many computing, design, and management projects in industry, academia, and government $[4,9,40]$. Due to its widespread adoption, there are many variations of $\mathrm{HCD}$ that differ in how people are brought into design processes, as well as in how and to what degree their needs, context, and requirements are captured. For example, Steen identifies participatory design, ethnography, the lead user approach, contextual design, co-design, and empathic design as six of the current approaches used by researchers and practitioners in human-centred design projects [40]. Each approach has its distinct theoretical roots and methods (e.g. role-playing, brainstorming, observations, co-creating prototypes), and each appeals to a slightly different subset of design projects [40].
HCD is globally recognised and shaped through its international standard, ISO 9241-210:2010. International standards are "documents that provide requirements, specifications, guidelines or characteristics that can be used consistently to ensure that materials, products, processes and services are fit for their purpose" [15]. Standards have wide-reaching influence on thousands of products, designs, and processes; they are created through consensus by standards organisations, such as the International Organization for Standardization, and adopted locally by other organisations, governments, and businesses [15]. Individual academics from multidisciplinary communities have been amongst those engaging with standards development for over two decades [18, pp. 83-92]. Many international standards influence computing and design processes, including standards related to web accessibility, privacy, and research involving human subjects $[18,19]$.

HCD's ISO "is intended for use by those responsible for planning and managing projects that design and develop interactive systems" [16]. It draws on the "substantial body of human factors/ergonomics and usability knowledge about how human-centred design can be organised and used effectively" [16] and presents six guiding principles for HCD projects (i.e. "the design is based upon an explicit understanding of users, tasks and environments; users are involved throughout design and development; the design is driven and refined by user-centred evaluation; the process is iterative; the design addresses the whole user experience; the design team includes multidisciplinary skills and perspectives" [16]). The ISO also provides guidelines for planning HCD projects, and a description of "four linked human-centeed design activities [that] shall take place during the design of any interactive system" [16].

\subsection{The limits of HCD and ISO 9241-210:2010}

Whilst HCD and its ISO have been effective at delivering some very popular and effective interactive systems, the human-centred approach to design is decidedly narrow. Its narrow focus has attracted criticism from a variety of perspectives, including from Don Norman, who is-in many communities-considered a leading figure in HCD [20]. In 2005, Norman claimed that "the focus upon [designing for] the human may be misguided" [27]. Norman's concerns stemmed from his observation that "the focus upon individual people (or groups) might improve things for them at the cost of making it worse for others. The more something is tailored for the particular likes, dislikes, skills, and needs of a particular target population, the less likely it will be appropriate for others" [27]. He suggested that shifting the focus of design away from humans, towards activities, would be a potential solution to this problem [27]. He proposed that this more broadly focused approach could be labelled "Activity-centred Design" and he believed it would deliver more functional, timeless interactive artefacts. Norman's critique inspired many other researchers to question HCD [26], including its limited conceptualisation of challenges related to sustainability [38].

In his 2009 interactions article, Schweikardt uses several examples of user-centred design (UCD) to highlight how it "is in fact an incomplete philosophy that lacks a sense of responsibility for concerns other than those of the immediate end user" [38]. For Schweikardt, the functionality of thick plastic bags and size of SUVs 
are two examples of how UCD can deliver exactly what people and companies want, but ignore the larger socio-environmental impact of those products. He argues that similar types of UCD and HCD-driven designs have contributed to the serious environmental degradation that we are facing today, emphasising that his "criticism is more than a call for greater sensitivity to the environment; it is also an acknowledgement that reliance on our understanding of our users' needs has gotten us into this mess" [38]. Schweikardt closes his article by calling on the interaction design community to drastically and quickly re-conceptualise its approaches. He acknowledges the difficulty of doing so, noting that "not only do we suffer from a lack of design theory that takes emergent, complex systems into account, but we also lack solid analytical theories of these systems" [38].

During a time frame that overlaps with Schweikardt's publication, the committee responsible for drafting and publishing HCD's ISO opted to incorporate "sustainability" into the ISO's text. Since 2010, there has been a section on "sustainability and HCD", which claims that "HCD directly support the first two pillars of sustainability: economic and social" [16]. The ISO begins by claiming that it "provides requirements and recommendations for HCD principles and activities throughout the life cycle of computer-based interactive systems" [16], but there is little to support these claims beyond vague statements about taking "into account the total life cycle costs of the product" [16]. Even the section on sustainability features only a brief assertion that HCD supports economic and social sustainability. These narrow and vague conceptions of sustainability offer room for improvement. We discuss some of those specific opportunities for improvement later in the paper.

Critiques of HCD and its ISO have extended to other issues, as well. Realpe-Muñoz et al. raise concerns about HCD and ISO 9241210 's lack of consideration of user security and privacy. They claim that "there is no process, qualitative and quantitative, that describes how to develop and validate systems taking into account the design requirements and principles (also called heuristics) allowing a good trade-off between security and usability, that is a user-centered design process for usable security and user authentication" [33] Heimgartner questioned the international validity of HCD and its ISO, by explaining that they are too rigid to adapt to local cultural contexts [12]. Although these critiques will not play a central role in our point about expanding the scope of HCD and its ISO to include objects, animals, and environmental ecosystems, we believe they are incredibly important to broader discussions about reconceptualising design theory. A design process or theory that inflexibly ignores security and culture is not suitable for today's global challenges.

\subsection{Moving beyond anthropocentricity: incorporating environmental ecosystems, animals, and objects}

We, the authors, align ourselves with Norman and Schweikardt, who both declare that focusing purely on human needs is insufficient. Furthermore, Norman's suggestion that we should focus our design efforts on activities resonates with our individual projects related to design activities [34], food preparation at home [6], and public policy development [43]. However, we feel that Norman and Schweikardt's perspectives fall slightly short of our broader environmental and social justice ambitions. We believe HCD should expand beyond its anthropocentric scope by incorporating interaction design approaches and concepts that address ecosystems, animals, and objects. In this section, we introduce and discuss three existing design concepts: Sustainable Interaction Design (SID), Animal-Computer Interaction (ACI), and Object Oriented Ontology (OOO). We also briefly describe what these concepts can and cannot offer to a reimagining of $\mathrm{HCD}$ and its ISO.

2.2.1 Sustainable interaction design. Blevis introduced SID in 2007 [2], inspiring a wave of 'explosive activity' related to environmental sustainability within HCI [7]. In his original paper, Blevis asserts that environmental sustainability should be a central focus of all interaction design projects. He describes how HCI researchers and practitioners can think about sustainability and interaction design through five principles of design: linking invention and disposal, promoting renewal and reuse, promoting quality and equality, de-coupling ownership and identity, and using natural models and reflection [2]. The principles, as well as his rubric for assessing material effects, are intended to help designers connect their design, development, and use of digital technologies with their requisite physical materials and natural resource consumption [2]. Roedl, Odom and Blevis recently conducted a retrospective analysis of work inspired by SID, and found that "research over the last ten years has yielded considerable insight into both the challenges and opportunities that exist for creating long-lasting, environmentally sustainable technologies" [36].

These well-documented challenges and opportunities, as well as Blevis's original principles and rubric, offer appropriate avenues through which to reimagine HCD and its ISO. SID begins to shift the focus of design away from the narrow wants and needs of humans, and towards a broader conceptualisation of how existing materials and natural resources are influenced by design decisions. For example, one of the five original principles of SID is linking invention and disposal, which states that "any design of new objects or systems with embedded materials of information technologies is incomplete without a corresponding account of what will become of the objects or systems that are displaced or obsoleted by such inventions" [2]. Adding such an account of displaced objects and systems to the planning phases and activities related to every HCD project would be a way to de-centre the human by accounting for the material effects of a design. Similarly, incorporating principle two-promoting renewal and reuse by documenting "the possibilities for renewal and reuse of existing objects or systems" [2]-would de-centre the human by once again forcing designers to account for the material effects of their work.

Although bringing SID into HCD's ISO would be a strong start to de-centering humans [2], SID falls short of solely being able to help us reimagine HCD's effects on earth's biophysical systems. For example, there is little in SID to help us consider the effects of interaction design on global waterways, air quality, or animal habitats. Although SID-inspired research has examined-or at least mentioned-the environmental effects of electronics waste [35], and the relationship between practices and the carbon footprint of digital technologies $[1,11,31]$, there is very little from the original SID principles that speaks directly to measuring and understanding 
interactive system effects on ecosystems. For this, we may need to draw directly from research on earth's biophysical limits (e.g. [41]) or environmental management ISOs (e.g. the ISO 14000 family).

2.2.2 Animal-computer interaction. Animal-computer interaction is a nascent field of study that "aims to expand the boundaries of Interaction Design by developing a user-centred approach to the design of technology intended for animals" [22]. It does this by "placing animals-as individuals and technology users, legitimate stakeholders and design contributors-and their interests at the centre of the design process" [22]. There is no established ACI rubric or set of principles comparable to those in SID, but a great deal of ACI discusses the ethics of designing for and with animals, as well as the importance of ensuring animal welfare in the design process [22, 32, 47].

Ethical considerations related to designing for and with animals are still highly contested within academic institutions. As Mancini explains, "currently the involvement of animals in the development of technology intended for them still falls under the ethical frameworks that regulate their use according to national and international legislation (e.g. European Directive, 2010/63/EU). Within these frameworks animals are essentially viewed as research instruments, unable to understand and consent to procedures that may harm them, rather than research participants and design contributors with their own interests. The aim of current frameworks is to minimise any negative impact of the research on the welfare of the individual animals involved (typically through the implementation of the principles of replacement, reduction and refinement [24]; however, this minimisation is subordinated to specific scientific interests and to the integrity of the procedures required to serve those interests, provided that the interests in question are deemed of sufficient societal significance. This approach is essentially different from that taken by ethical frameworks regulating the involvement of humans in research, including within ID, where the interests of the individual participant are prioritised over the interests of science and society" [22].

To overcome these challenges and help researchers take animal welfare seriously in design-rather than just viewing animals as research instruments-Väätäjä and Pesonen conducted a literature review of 'international animal welfare associations', animal behaviour societies', as well as other relevant societies' and organizations' webpages and publications searching for guidelines to carry out studies and research with animals." [47]. Through this, they developed 23 guidelines for researchers interested in conducting animal-centred research: "seven are related to the time prior to study, eight [for] when carrying out the study, seven for reporting the study and one general guideline" [47]. Their guidelines cover a number of important issues, including the need for researchers to get appropriate training in how to habituate animals to research environments (or to habituate themselves to animal environments), not using aversive methods (i.e. methods that cause pain in or harm to the animals), and giving animals the opportunity to withdraw from participation [47].

These guidelines, as well as ACI's aim to expand the boundaries of interaction design, offer appropriate avenues through which to broadly reimagine HCD and its ISO. Animal-centred interaction design is, by its very name and nature, a non-anthropocentric endeavour. However, ACI still relies heavily on making itself "consistent with a user-centred and participant-centred perspective" [22], merely placing animals at the centre of design decisions instead of humans. This means that, despite some claims ACI will be useful for achieving sustainability goals [21], it will likely be an equally problematic design approach to HCD. In short, whilst ACI offers valuable insights-particularly in terms of arguing the importance of ethics for non-human research participants-it is equally unable to solely help us reimagine HCD's relationship with objects and earth's biophysical systems.

2.2.3 Object oriented ontology. Object oriented ontology (OOO) is not an information science or engineering ontology; OOO does not offer an "explicit formal specifications of the terms in [a] domain and relations among them" [28]. Rather, OOO is a strand of philosophy that is becoming popular amongst some designers, and in some cases is inspired by Actor-Network Theory. OOO "puts objects at the centre of being. In OOO's terms, all conceivable entities (including humans) are 'objects', 'things', or 'stuff'. All entities are deserving of equal consideration. Hence $\mathrm{OOO}$ is termed a 'flat ontology'; no object is more significant than any other object" [20]. That said, there is considerable debate and disagreement about what counts as an 'object' in OOO: "sometimes [object] refers to solid inanimate objects as opposed to humans, animals, concepts or events. More often it serves as half of the modern subject/object dualism and this promotes the misunderstanding that OOO prefers inanimate objects to humans" [10].

Important debates about what 'counts' as an object aside, what OOO could bring to HCD and its ISO is its flat, non-hierarchical way of thinking about design [20,23]. Humans must necessarily be de-centred from design processes if we were to embrace OOO's idea that "objects of all shapes and sizes, from football teams to FermiDirac condensates or, if you prefer something more ecological, from nuclear waste to birds' nests" [23] are important actants in and of design. Unfortunately, aside from Bogost's Alien Phenomenology (AP) [3] and Lindley and Coulton's forthcoming application of AP to IoT [20], there are few specific examples of how we might translate this philosophical, non-hierarchical approach into actual design processes.

\section{EXPANDING HCD'S ISO}

In this section, we try to clarify our ideas by quoting sections of ISO 9241-210:2010 and discussing specific changes that could be made by integrating the aforementioned notions from SID, ACI, and OOO. Due to time constraints and the maintain a certain depth of discussion, we have opted to focus on one specific section of HCD's ISO: section 4, the principles of HCD. We do not mean to suggest that other sections do not demand a critical examination and reimagining. The sections outlining the scope of, rationale for adopting, and activities underpinning ISO 9241-210:2010 absolutely demand a thorough and critical engagement; however, we have opted to start by reimagining just one section, intentionally leaving the others for discussion at LIMITS.

Much of the forthcoming discussion hinges on ISO 9241-210:2010's existing, narrow definitions of the terms 'user' and 'stakeholder'. User is currently defined in the ISO as a "person who interacts with the product" [16]. We believe that SID, ACI, and OOO implore 
us to push for an expansion of that definition, such that a 'user' would instead be an object, person, animal, or ecosystem that interacts with the product. Similarly, a stakeholder is currently defined as an "individual or organisation having a right, share, claim or interest in a system or in its possession of characteristics that meet their needs and expectations" [16]. We believe that SID, ACI, and OOO implore us to push for an expansion of that definition, such that a 'stakeholder' would instead be an object, person, animal, ecosystem or organisation having a right, share, claim or interest in a system or in its possession of characteristics that meet their needs and expectations.

When we use the terms 'user' and 'stakeholder' in our proposed amendments to HCD's ISO, we do so with the assumption that the terms will have been expanded to reflect our broadened definitions.

\subsection{Section 4: Principles of HCD}

3.1.1 4.1 General. The principles of HCD explain that "whatever the design process and allocation of responsibilities and roles adopted, a human-centred approach should follow the principles listed below:

(1) the design is based upon an explicit understanding of users, tasks and environments (see 4.2);

(2) users are involved throughout design and development (see 4.3);

(3) the design is driven and refined by user-centred evaluation (see 4.4);

(4) the process is iterative (see 4.5);

(5) the design addresses the whole user experience (see 4.6);

(6) the design team includes multidisciplinaary skills and perspectives (see 4.7)." [16, pp. 5]

Each of these principles is described in detail in the ISO, and we believe that they could each be expanded to include ecosystems, animals, and objects.

3.1.2 4.2 The design is based upon an explicit understanding of users, tasks and environments. This section currently states that "products, systems and services should be designed to take account of the people who will use them as well as other stakeholder groups, including those might be affected (directly or indirectly) by their use. Therefore, all relevant user and stakeholder groups should be identified. Constructing systems based on an inappropriate or incomplete understanding of user needs is one of the major sources of systems failure" [16].

In line with SID's principles, we believe that this could be expanded to more explicitly include objects, animals, and ecosystems that could be displaced by new designs. We believe that it could be updated to read: "products, systems and services should be designed to take account of the people, animals, objects, or ecosystems who will use them as well as other stakeholder groups, including those might be affected (directly or indirectly) by their use. Products, systems and services should also be designed to take account of what will become of the objects or systems that are displaced or being made obsolete by such inventions. Therefore, all relevant user and stakeholder groups should be identified. Constructing systems based on an inappropriate or incomplete understanding of user needs is one of the major sources of systems failure".
3.1.3 4.3 Users are involved throughout design and development. This sections describes which users should be involved in the design and development of products, systems and services. Much of this section will carry new meaning with our updated definitions of 'user' and 'stakeholder'. However, we would encourage one change to the following sentence: "the people who are involved should have capabilities, characteristics and experience that reflect the range of users for whom the system is being designed" [16]. We would prefer its scope to be expanded to read "the people, animals, objects, and ecosystems involved should have capabilities, characteristics and experience that reflect the range of users for whom the system is being designed".

3.1.4 4.6 The design addresses the whole user experience. This section will require significant changes in our reimagined ISO. Its original paragraph would need to be expanded to instead read that "user experience is a consequence of the presentation, functionality, system performance, interactive behaviour, environmental footprint and assistive capabilities of an interactive system, both hardware and software. It is also a consequence of the user's prior experiences, ownership of objects, attachment to objects, attitudes, skills, habits and personality. There is a common misconception that usability refers solely to making products easy to use. However, the concept of usability used in ISO 9241 is broader and, when interpreted from the perspective of the users' personal goals, skills, meaning, knowledge and attachment can include the kind of perpetual, and emotional aspects typically associated with user experience, as well as issues such as embodied carbon, and possibilities for renewal and reuse of existing objects or systems" [16].

The second paragraph would also need to be expanded, such that it would state that "designing for the user's experience involves considering, where appropriate, organisational impacts, local and global ecosystem effects, what will become of the objects or systems that are displaced or being made obsolete by such inventions, the possibilities for renewal and reuse of existing objects or systems, user documentation, online help, support and maintenance (including help desks and customer contact points), training, long-term use, and product packaging (including visible life-cycle costs the 'out-of-box experience'). The current state of $\mathrm{CO}^{2}$ in the atmosphere, the user's experience of previous or other systems and issues such as branding and advertising should also be considered. The need to consider these different factors and their interdependencies has implications for the project plan" [16].

3.1.5 Sections 4.4, 4.5, and 4.7. We believe that these sections will need little modification once the ISO includes our updated definitions of 'user' and 'stakeholder'.

\subsection{Engaging with the ISO development process}

If we wish to make progress on these ideas, we will eventually need to engage with the development processes for ISO 9241-210:2010. Fortunately, the International Organisation for Standardization (IOS) "has made a commitment to develop 'standards for a sustainable world"' [16, pp. 27], which suggest they should be open to having the types of discussions contained within our proposed changes. With that in mind, we must be aware that it can take 
up to three years to develop or redevelop a standard; deliberation, discussion, and voting amongst members can take time [13]. As the IOS explains, "the voting process is the key to consensus. If that's achieved then the draft is on its way to becoming an ISO standard. If agreement isn't reached then the draft will be modified further, and voted on again" [13]. Voting and discussion are open to members of the ISO's technical committee.

In short, if we want to influence the development of HCD's ISO, we need to join or advocate directly to its technical committee, ISO/TC 159/SC 4 [14]. HCD's ISO was last reviewed and confirmed in 2015 [14]. It will be reviewed again every five years, meaning the next review will take place in 2020. Between now and then, there are several actions we could take: we could reach out to ISO/TC 159/SC 4's chair person, who is currently Mr. Ben Hedley [14], and offer him insights or recommendations via email. We could attempt to engage with ISO/TC 159/SC 4's forthcoming meeting, scheduled to take place in December 2017. Before any of this happens, we could also collectively debate and discuss more specific suggestions for reshaping HCD. There appears to be a significant amount of momentum within academic communities to challenge anthropocentric research (e.g. [20, 22, 27, 42]); engaging with and challenging HCD's ISO is one way for us to extend our critiques to industry and government.

\subsection{Reflections on this discussion}

We wanted to close this paper by offering some brief reflections about what we've just discussed. Our ideas are at a very early stage of development, and we wished to share them, despite their early development, to spark a dialogue with fellow attendees at LIMITS 2017. Our ideas have grown out of our ongoing work related to public policies and other governmental instruments (e.g. regulations, laws, standards), which simultaneously perpetuate and challenge interaction design's status quo [43]. We wanted to narrow our focus to HCD and its ISO because of their ubiquity, popularity, and wide-reaching influence. We recognise that engaging with ISO development is itself an activity with 'limits'; there are brief windows of opportunities to engage with and influence ISO development, and missing that window can mean waiting for another five years. But we believe it is a valuable endeavour to pursue, especially because of the wide-reaching influence of ISOs.

Our reviewers kindly raised several important issues that we have not yet had time to thoroughly address. For example, one reviewer noted that there are likely many lessons to be drawn from other literature that we have excluded from this paper (e.g. research on sustainable engineering practices, environmental determinism, and political ecology). We agree and we hope that other specialists in those areas contribute to this emerging discussion, in ways and using theories that we have neglected here. That same reviewer also raised an important question about including "communities" in our expanded definition of users. We have not included that suggestion in this iteration of the paper's text; however, we do believe it highlights an interesting dilemma about what should or could be included in an expanded definition of "users". For example, insects and bacteria are not explicitly named in our re-imagining of HCD, even though they play important roles in ecosystems. Moreover, if we expand our definition of "users" to include communities, might we also expand our definition to include other types of assemblages of peoples, animals, and objects? The IOS promotes a multi-actor approach to sustainable development [46]; should we simply align ourselves with that? We have no firm answers to or opinions on these questions and issues yet. We hope to discuss them during the LIMITS workshop.

We would also like to openly reflect upon is some of our unstated motivations; when we wrote this paper, we wanted to align ourselves with those calling for a reimagining of $\operatorname{HCD}[27,38]$, as well as those seeking to understand "human and nonhuman actants operating in distributed assemblages of practice" [42]. As Väätäjä and Pesonen assert, "all HCI studies need to take ethical issues into account and ensure the ethical justification of the research, technology development and interventions" [47]. We believe this needs to extend to the planet, animals, and our diverse array of existing objects. We would appreciate see something akin to Bolivia's recognition of the planet's fundamental natural rights [48] or New Zealand's recent granting of human rights to a river [37] adopted broadly within computing and academic communities. We also suspect we could learn from long-established Indigenous epistemologies, which have often been ignored-or intentionally erased-by Western scholars and legal systems [44]. But we recognise that there could be many challenges that stem from pushing and adopting this level of change; in particular, there is a degree of sensitivity that would be required to make these changes-both in terms of how we approach the HCD community, and how we work with and learn from Indigenous epistemologies.

As interaction designers ourselves, we recognise the difficulty of executing projects with the level of complexity we have described here. Ultimately, we believe the complex cultural changes and design challenges that we have highlighted here are valuable endeavours for us-especially, as privileged academics-to pursue. And we believe this particularly applies to people who hope to take the limits of earth's biophysical systems seriously. We believe we need to start targeting the worldviews and frameworks that perpetuate the status quo, and that ISOs are one of the tools used to perpetuate that status quo. As implied in this paper, we have a broad range of exciting research theories and tools to draw on, so let's try to change HCD and its ISO.

\section{CONCLUSION}

In this paper, we questioned the anthropocentricity of HCD and its ISO. We outlined some of the existing critiques of HCD, and made a case for why and how Sustainable Interaction Design (SID), Object Oriented Ontology (OOO), and animal-computer interaction (ACI) might be able to expand the boundaries of HCD. We also highlighted specific parts of the HCD ISO that could be adjusted to accommodate environmental, animal, and object-related considerations that are currently lacking from the ISO. Through this, we contributed a preliminary set of ideas about what should change with HCD and its ISO. We closed by highlighting some of the issues we hope to discuss in greater detail at LIMITS, and by calling for environmentally concerned researchers to engage with the future development of HCD's ISO. 


\section{ACKNOWLEDGEMENTS}

We would like to thank all of the reviewers who contributed to this document, as well as the LIMITS organisers and participants for being open to this discussion. Vanessa would like to thank the Digital Economy programme (RCUK Grant EP/G037582/1), which supports the HighWire Centre for Doctoral Training (highwire.lancs.ac.uk). She would also like to thank C02K31YADRVG, C02QK6EDG8WN, CB5A24N59J, and the dozens of other objects, animals, and digital technologies and services that supported her throughout this publication process.

\section{REFERENCES}

[1] Oliver Bates, Mike Hazas, Adrian Friday, Janine Morley, and Adrian K. Clear 2014. Towards an Holistic View of the Energy and Environmental Impacts of Domestic Media and IT. In Proceedings of the SIGCHI Conference on Human Factors in Computing Systems (CHI '14). ACM, New York, NY, USA, 1173-1182. https://doi.org/10.1145/2556288.2556968

[2] Eli Blevis. 2007. Sustainable Interaction Design: Invention \& Disposal, Renewal $\&$ Reuse. In Proceedings of the SIGCHI Conference on Human Factors in Computing Systems (CHI '07). ACM, New York, NY, USA, 503-512. https://doi.org/10.1145/ 1240624.1240705

[3] Ian Bogost. 2012. Alien Phenomenology, or What Itfis Like to Be a Thing. University of Minnesota Press. http://www.jstor.org/stable/10.5749/j.ctttsdq9

[4] Paula L. Brown. 2016. Human-Centered Design in the US Federal Government. Government Innovators Network Blog (2016). https://www.innovations.harvard. edu/awards-programs/bright-ideas

[5] Jay Chen. 2016. A Strategy for Limits-aware Computing. In Proceedings of the Second Workshop on Computing Within Limits (LIMITS '16). ACM, New York, NY, USA, Article 1, 6 pages. https://doi.org/10.1145/2926676.2926692

[6] Adrian K. Clear, Mike Hazas, Janine Morley, Adrian Friday, and Oliver Bates. 2013. Domestic Food and Sustainable Design: A Study of University Student Cooking and Its Impacts. In Proceedings of the SIGCHI Conference on Human Factors in Computing Systems (CHI '13). ACM, New York, NY, USA, 2447-2456. https://doi.org/10.1145/2470654.2481339

[7] Carl DiSalvo, Phoebe Sengers, and Hrönn Brynjarsdóttir. 2010. Mapping the Landscape of Sustainable HCI. In Proceedings of the SIGCHI Conference on Human Factors in Computing Systems (CHI '10). ACM, New York, NY, USA, 1975-1984. https://doi.org/10.1145/1753326.1753625

[8] Susan Gasson. 2003. Human-centered vs. user-centered approaches to information system design. FITTA : fournal of Information Technology Theory and Application 5, 2 (2003), 29-46. https://search.proquest.com/docview/200009053? accountid=11979 Copyright - Copyright Ken Peffers, DBA JITTA : Journal of Information Technology Theory \& Application 2003; Document feature - references; Last updated - 2010-06-06.

[9] Joseph Giacomin. 2014. What Is Human Centred Design? The Design fournal 17, 4 (2014), 606-623. https://doi.org/10.2752/175630614X14056185480186

[10] Graham Harman. 2015. Object-Oriented Ontology. Palgrave Macmillan UK London, 401-409. https://doi.org/10.1057/9781137430328_40

[11] Mike Hazas, Janine Morley, Oliver Bates, and Adrian Friday. 2016. Are There Limits to Growth in Data Traffic?: On Time Use, Data Generation and Speed. In Proceedings of the Second Workshop on Computing Within Limits (LIMITS '16) ACM, New York, NY, USA, Article 14, 5 pages. https://doi.org/10.1145/2926676. 2926690

[12] Rüdiger Heimgärtner. 2014. ISO 9241-210 and Culture? - The Impact of Culture on the Standard Usability Engineering Process. Springer International Publishing, Cham, 39-48. https://doi.org/10.1007/978-3-319-07638-6_5

[13] International Organization for Standardization. 2017. How we develop standards. https://www.iso.org/developing-standards.html. (2017).

[14] International Organization for Standardization. 2017. ISO 9241-210:2010 https://www.iso.org/standard/52075.html. (2017).

[15] International Organization for Standardization. 2017. We're ISO: we develop and publish International Standards. https://www.iso.org/standards.html. (2017).

[16] ISO 9241-210:2010(en) 2010. Ergonomics of human-system interaction - Part 210: Human-centred design for interactive systems. Standard. International Organization for Standardization, Brussels.

[17] Alan J. Jamieson, Tamas Malkocs, Stuart B. Piertney, Toyonobu Fujii, and Zulin Zhang. 2017. Bioaccumulation of persistent organic pollutants in the deepest ocean fauna. Nature Ecology and Evolution 1, 0051 (2017), 31-4. https://doi.org/ 10.1038/s41559-016-0051

[18] Jonathan Lazar, Julio Abascal, Simone Barbosa, Jeremy Barksdale, Batya Friedman, Jens Grossklags, Jan Gulliksen, Jeff Johnson, Tom McEwan, Loïc Martínez Normand, Wibke Michalk, Janice Tsai, Gerrit van der Veer, Hans von Axelson, Ake Walldius, Gill Whitney, Marco Winckler, Volker Wulf, Elizabeth F. Churchill,
Lorrie Cranor, Janet Davis, Alan Hedge, Harry Hochheiser, Juan Pablo Hourcade, Clayton Lewis, Lisa Nathan, Fabio Paterno, Blake Reid, Whitney Quesenbery, Ted Selker, and Brian Wentz. 2016. Human-Computer Interaction and International Public Policymaking: A Framework for Understanding and Taking Future Actions. Foundations and Trends ${ }^{\circledR}$ Human-Computer Interaction 9, 2 (2016), 69-149. https://doi.org/10.1561/1100000062

[19] Jonathan Lazar, Julio Abascal, Janet Davis, Vanessa Evers, Jan Gulliksen, Joaquim Jorge, Tom McEwan, Fabio Paternò, Hans Persson, Raquel Prates, Hans von Axelson, Marco Winckler, and Volker Wulf. 2012. HCI Public Policy Activities in 2012: A 10-country Discussion. interactions 19, 3 (May 2012), 78-81. https: //doi.org/10.1145/2168931.2168947

[20] Joseph Galen Lindley, Paul Coulton, and Rachel Cooper. 2017. Why the internet of things needs object orientated ontology.

[21] Clara Mancini. 2013. Animal-computer Interaction (ACI): Changing Perspective on HCI, Participation and Sustainability. In CHI '13 Extended Abstracts on Human Factors in Computing Systems (CHI EA '13). ACM, New York, NY, USA, 2227-2236. https://doi.org/10.1145/2468356.2468744

[22] Clara Mancini. 2017. Towards an animal-centred ethics for Animalfi?!Computer Interaction. International fournal of Human-Computer Studies 98 (2017), 221 233. https://doi.org/10.1016/j.ijhcs.2016.04.008

[23] Timothy Morton. 2011. Here Comes Everything: The Promise of Object-Oriented Ontology. Qui Parle 19, 2 (2011), 163-190.

[24] W.M.S. Mussell and R.L Burch. 1958. The principles of humane experimental technique. Johns Hopkins University, Baltimore, MD. http://altweb.jhsph.edu/ pubs/books/humane_exp/het-toc

[25] Nature News. 2017. Daring deep-sea explorers, army worm offensive and GM-rice theft. Nature 452 (2017), 396fi?!397. https://doi.org/10.1038/542396a

[26] Donald A. Norman. 2005. HCD harmful? A Clarification. Don Norman: Designing for People (Sept. 2005). http://www.jnd.org/dn.mss/hcd_harmful_a_clari.html

[27] Donald A. Norman. 2005. Human-centered Design Considered Harmful. interactions 12, 4 (July 2005), 14-19. https://doi.org/10.1145/1070960.1070976

[28] Natalya F. Noy and Deborah L. McGuinness. 2001. Ontology Development 101: A Guide to Creating Your First Ontology. Technical Report. Stanford Knowledge Systems Laboratory Technical Report KSL-01-05 and Stanford Medical Informatics Technical Report SMI-2001-0880.

[29] Daniel Pargman, Elina Eriksson, and Adrian Friday. 2016. Limits to the Sharing Economy. In Proceedings of the Second Workshop on Computing Within Limits (LIMITS '16). ACM, New York, NY, USA, Article 12, 7 pages. https://doi.org/10. $1145 / 2926676.2926683$

[30] Birgit Penzenstadler, Ankita Raturi, Debra Richardson, M. S. Silberman, and Bill Tomlinson. 2015. Collapse (and other futures) software engineering. First Monday 20, 8 (2015). http://firstmonday.org/ojs/index.php/fm/article/view/6123

[31] Chris Preist, Daniel Schien, and Eli Blevis. 2016. Understanding and Mitigating the Effects of Device and Cloud Service Design Decisions on the Environmental Footprint of Digital Infrastructure. In Proceedings of the 2016 CHI Conference on Human Factors in Computing Systems (CHI '16). ACM, New York, NY, USA, 1324-1337. https://doi.org/10.1145/2858036.2858378

[32] Jean-Loup Rault, Sarah Webber, and Marcus Carter. 2015. Cross-disciplinary Perspectives on Animal Welfare Science and Animal-computer Interaction. In Proceedings of the 12th International Conference on Advances in Computer Entertainment Technology (ACE '15). ACM, New York, NY, USA, Article 56, 5 pages. https://doi.org/10.1145/2832932.2837014

[33] Paulo Realpe-Muñoz, Cesar A. Collazos, Julio Hurtado, Toni Granollers, and Jaime Velasco-Medina. 2016. An Integration of Usable Security and User Authentication into the ISO 9241-210 and ISO/IEC 25010:2011. Springer International Publishing, Cham, 65-76. https://doi.org/10.1007/978-3-319-39381-0_7

[34] Christian Remy, Silke Gegenbauer, and Elaine M. Huang. 2015. Bridging the Theory-Practice Gap: Lessons and Challenges of Applying the Attachment Framework for Sustainable HCI Design. In Proceedings of the 33rd Annual ACM Conference on Human Factors in Computing Systems (CHI '15). ACM, New York, NY, USA, 1305-1314. https://doi.org/10.1145/2702123.2702567

[35] Christian Remy and Elaine M. Huang. 2015. Addressing the Obsolescence of EndUser Devices: Approaches from the Field of Sustainable HCI. In ICT Innovations for Sustainability, Lorenz M. Hilty and Bernard Aebischer (Eds.). Advances in Intelligent Systems and Computing, Vol. 310. Springer International Publishing, 257-267. https://doi.org/10.1007/978-3-319-09228-7_15

[36] David Roedl, Will Odom, and Eli Blevis. 2017. Three Principles of Sustainable Interaction Design, Revisited. Routledge. https://doi.org/forthcoming

[37] Eleanor Ainge Roy. 2017. New Zealand river granted same legal rights as human being. https://www.theguardian.com/world/2017/mar/16/new-zealand-rivergranted-same-legal-rights-as-human-being. (2017).

[38] Eric Schweikardt. 2009. SUSTAINABLY OURS: User Centered is off Center. interactions 16, 3 (May 2009), 12-15. https://doi.org/10.1145/1516016.1516019

[39] M. S. Silberman. 2015. Information systems for the age of consequences. First Monday 20, 8 (2015). http://firstmonday.org/ojs/index.php/fm/article/view/6128

40] Marc Steen. 2011. Tensions in human-centred design. CoDesign 7, 1 (2011), 45-60. https://doi.org/10.1080/15710882.2011.563314 
[41] Will Steffen, Katherine Richardson, Johan Rockstrm, Sarah E. Cornell, Ingo Fetzer, Elena M. Bennett, Reinette Biggs, Stephen R. Carpenter, Wim de Vries, Cynthia A. de Wit, Carl Folke, Dieter Gerten, Jens Heinke, Georgina M. Mace Linn M. Persson, Veerabhadran Ramanathan, Belinda Reyers, and Sverker Srlin. 2015. Planetary boundaries: Guiding human development on a changing planet. Science 347, 6223 (2015). https://doi.org/10.1126/science.1259855

[42] Yolande Strengers, Larissa Nicholls, and Cecily Maller. 2016. Curious energy consumers: Humans and nonhumans in assemblages of household practice. Journal of Consumer Culture 16, 3 (2016), 761-780. https://doi.org/10.1177/ 1469540514536194

[43] Vanessa Thomas, Christian Remy, Michael Hazas, and Oliver Bates. 2017. HC and environmental public policy: opportunities for engagement. In $\mathrm{CHI}$ '17 Proceedings of the 35th Annual ACM Conference on Human Factors in Computing Systems. May 06-11, 2017, Denver, CO, USA. ACM. https://doi.org/10.1145/3025453.
3025579

[44] Zoe Todd. 2014. Fish pluralities: Human-animal relations and sites of engagement in Paulatuuq, Arctic Canada. Qutudes/Inuit/Studies 38, 1-2 (2014), 217-238.

[45] Jeff Tollefson. 2017. Giant crack in Antarctic ice shelf spotlights advances in glaciology. Nature 452 (2017), 402-403. https://doi.org/10.1038/nature.2017.21507

[46] Sandrine Tranchard. 2016. New ISO standard to help communities manage sustainable development. https://www.iso.org/news/2016/07/Ref2101.html. (2016).

[47] Heli K. Väätäjä and Emilia K. Pesonen. 2013. Ethical Issues and Guidelines when Conducting HCI Studies with Animals. In CHI'13 Extended Abstracts on Human Factors in Computing Systems (CHI EA '13). ACM, New York, NY, USA, 2159-2168. https://doi.org/10.1145/2468356.2468736

[48] John Vidal. 2011. Bolivia enshrines natural world's rights with equal status for Mother Earth. The Guardian (2011). https://www.theguardian.com/environment/ 2011/apr/10/bolivia-enshrines-natural-worlds-rights 